\title{
KILAT
}

Vol. 10, No. 1, April 2021, P-ISSN 2089-1245, E-ISSN 2655-4925

DOI: https://doi.org/10.33322/kilat.v10i1.1156

\section{Penerapan Metode Adaptive Learning Untuk Pengembangan Pembelajaran Pada Mata Pelajaran Sains SD Berbasis Multimedia}

\author{
Eka Putra $^{\text {; }}$ Andi Dahroni ${ }^{2}$; Budi Prayitno ${ }^{3}$ \\ ${ }^{1,2,3}$ Institut Teknologi PLN \\ ${ }^{1}$ eka@itpln.ac.id \\ ${ }^{2}$ andidahroni@itpln.ac.id \\ ${ }^{3}$ budiprayitno@itpln.ac.id
}

\begin{abstract}
The world of education is currently very rapidly developing, especially in the area of technology usage. One of them is E-learning technology which supports students to be able to learn independently without being accompanied directly by the instructor. Making a learning interesting can also support students' enthusiasm to continue learning. For this reason, an interactive learning media is needed that can give students a more interesting learning experience supported by adaptive learning methods. Adaptive learning method is a method that provides a service or learning in accordance with the style possessed by someone, as for some learning styles that are generally owned by humans, namely: Visual, Auditory, Kinesthetic. so with this method the ability of a person will be increased because it can adjust to what style they have. Researchers will specialize in SAINS 1 grade elementary school subjects to make interactive learning multimedia. So later the results of this study are 3 types of multimedia learning science elementary (visual, auditory, kinesthetic) in accordance with the data that we will get at the place or case study that has been determined. The output of this research is scientific publications in national journals that are not accredited, Proceedings in National scientific meetings.
\end{abstract}

Keywords: Multimedia, Adaptive Learning, Learning, E-Learning, SCIENCE

\section{ABSTRAK}

Dunia Pendidikan saat ini sudah sangat berkembang pesat, khususnya pada bagian penggunaan teknologi. Salah satunya adalah teknologi E-learning yang menjadi penunjang siswa untuk dapat belajar dengan mandiri tanpa di damping langsung oleh pihak pengajar. Dengan Menjadikan sebuah pembelajaran itu menarik juga dapat penunjang semangat siswa untuk terus belajar. Untuk itu diperlukan sebuah media pembelajaran interactive yang dapat memberikan siswa pengalaman belajar yang lebih menarik dengan didukung metode adaptive learning. Metode adaptive learning adalah metode yang memberikan sebuah pelayanan atau pembelajaran sesuai dengan gaya yang dimiliki oleh seseorang, adapun beberapa gaya belajar yang umumnya dimiliki oleh manusia yaitu : Visual, Auditori, Kinestetik. jadi dengan adanya metode ini kemampuan seseorang akan lebih meningkat karena dapat menyesuaikan dengan gaya apa yang dimilikinya. Peneliti akan mengkhususkan pada mata pelajaran SAINS kelas 1 SD untuk dapat dibuatkan multimedia pembelajaran interactive nya. Jadi nanti hasil dari penelitian ini adalah 3 jenis multimedia pembelajaran sains SD (Visual, Auditori, Kinestetik ) sesuai dengan data yang akan kita dapatkan pada tempat atau studi kasus yang telah ditentukan. Luaran penelitian ini adalah publikasi ilmiah di jurnal nasional tidak terakreditasi, Prosiding dalam pertemuan ilmiah Nasional.

Kata kunci: Multimedia, Adaptive Learning, Pembelajaran, E-Learning, SAINS 


\section{PENDAHULUAN}

Mata pelajaran sains saat ini menjadi salah satu mata pelajaran wajib dibeberapa Sekolah Dasar di Indonesia. Munculnya mata pelajaran ini menjadi tantangan tersendiri bagi pihak penganjar di setiap Lembaga sekolah, yang mana mata pelajaran sains ini adalah mata pelajaran baru untuk kurikulum saat ini. Menurut Iskandar (1996/1997:2), ilmu pengetahuan alam atau science secara harfiah disebut sebagai ilmu tentang alam ini, ilmu yang mempelajari peristiwa-peristiwa yang terjadi di alam secara rasional dan objektif. MenurutPermendiknas No. 22 tahun 2006, Standar Isi mata pelajaran IPAuntuk SD/MI, IPA berhubungan dengan cara mencari tahu tentang alam secara sistematis, sehingga IPA bukan hanya penguasaan kumpulan pengetahuan yangberupa fakta-fakta, konsep-konsep,atau prinsip-prinsip saja, tetapi jugamerupakan suatu proses penemuan.Pendidikan IPA diharapkan menjadi wahanasiswa untuk mempelajari diri sendiri dan alam sekitar serta prospekpengem bangan lebih lanjut dalam menerapkannya di dalam kehidupan sehari-hari. Sirilius Seran (2016), mengatakan Makin tinggi pendidikan yang ditamatkan makin cepat mendapatkan pekerjaan.

Menjadi kewajiban bagi tenaga pengajar untuk dapat melakukan pembelajaran mata pelajaran yang diampu semaksimal mungkin walaupun perkembangan zaman sudah pesat dan cepat. Untuk itu juga dibutuhkan pelatihan bagaimana cara agar sebagai tenaga pengajar dapat mampu memberikan yang berkualitas khususnya yang berkembang sekarang pada bagian Teknologi.

Mustika, et all (2017) Media Pembelajaran memiliki peranan yang sangat penting pada proses perkuliahan. Penyajian media pembelajaran beraneka ragam, berupa grafik, film, slide, foto, serta pembelajaran dengan menggunakan komputer. Dalam media pembelajaran penggunaan media komputer berperan penting dalam menyalurkan, menyimpan dan memproses informasi, dimana proses belajar-mengajar menjadi komunikatif, efektif dan efisien.

Inung Diah Kurniawati,, et.al (2018). Hasil penelitian menunjukkan bahwa media pembelajaran yang dikembangkan masuk dalam $\mathrm{k}$ telah melakukan penelitian dalam bidang ilmu fisika dikarenakan pola pikir awal yang diketahui bahwa fisika adalam sebuah pelajaran yang sulit. Sehingga harus dicarikan suatu terobosan atau ide bagaimana agar membuat pelajaran ini menjadi sesuatu yang menarik dengan membuatkan sebuat multimedia pembelajaran. Dan kemudian setelah diuji coba kepada beberapa sampel maka multimedia media pembelajaran ini mendapatkan kriteria layak. Hal ini ditunjukkan dengan nilai rata-rata dari validasi ahli materi 3,3; ahli media 3,3; dan pengguna 3,4. Hasil tersebut masuk dalam kriteria layak.

Ence Surahman, et.al (2017) telah melakukan penelitian di bantu dengan metode adaptive learning dan di dukung oleh metode bleanded learning. Hasil penelitian berupa: (1) metode Adaptive Mobile Learning layak digunakan sebagai media pembelajaran berdasarkan validasi ahli materi, ahli media, dan pengguna dengan rerata kelayakan mencapai skor 3,35 dengan kategori "sangat baik"; (2) kebermanfaatan metode dibuktikan melalui perbedaan hasil belajar mencapai angka kenaikan sebesar 33,80 sesudah menggunakan produk Adaptive Mobile Learning dan terbukti mendukung blended learning dengan skor 3,42 dengan kategori "sangat baik".

I Gede Jana Adi Putra, Dkk (2019) Sistem adaptive learning pada penelitian ini bertujuan untuk dapat memberikan materi pembelajaran yang tingkat kesulitannya sesuai dengan kemampuan peserta didik, dan cara mempresentasikan materi pembelajarannya sesuai dengan gaya belajar peserta didik. Dengan kata lain, system adaptive learning dapat mengadaptasikan tampilannya menyesuaikan dengan karakteristik peserta didik, sehingga mempunyai efektivitas pembelajaran yang tinggi dan apresiasi atas pencapaian dari tingkat kemampuan setiap peserta didik. Penelitian ini 


\section{KILAT}

Vol. 10, No. 1, April 2021, P-ISSN 2089-1245, E-ISSN 2655-4925

DOI: https://doi.org/10.33322/kilat.v10i1.1156

mengadopsi metode adaptive learning untuk mengetahui tingkat kemampuan peserta didik dan Bayesian Network untuk mendeteksi gaya belajar peserta didik. Diharapkan penelitian ini mampu memberikan dan mendeteksi gaya belajar peserta didik, sehingga mampu menyediakan konten pembelajaran yang sesuai dengan gaya belajarnya.

Metode adaptive learning adalah metode yang memberikan sebuah pelayanan atau pembelajaran sesuai dengan gaya yang dimiliki oleh seseorang, adapun beberapa gaya belajar yang umumnya dimiliki oleh manusia yaitu : Visual, Auditori, Kinestetik. jadi dengan adanya metode ini kemampuan seseorang akan lebih meningkat karena dapat menyesuaikan dengan gaya apa yang dimilikinya. Dan kemudian digabungkan dengan yang nama teknologi multimedia yang dapat mengubah pola pikir siswa bahwa belajar juga dapat dilakukan dengan cara yang menyenangkan. Multimedia pembelajaran ini akan dibangun sangat interaktif dan tentunya di dasari dengan metode adaptive learning yang bertujuan agar suatu pembelajaran yang akan dilakukan tidak hanya dapat dilaksanakan di dalam kelas saja, tetapi juga bisa dilakukan dimanapun dan kapanpun. Hal ini pastinya nanti akan mendapatkan dukungan dari orang tua siswa, dengan hadirnya multimddia pembelajaran ini maka efek negatif dari adanya teknologipun dapat dikurangi.

Balqis Fallahnda (2020). Adaptive learning adalah metode belajar yang mengedepankan efektivitas dan efisiensi. Metode ini menganjurkan proses belajar-mengajar dirancang dan diterapkan sesuai dengan kebutuhan siswa, dengan menyediakan sumber pelajaran yang tepat. Selain itu, metode ini mengaplikasikan sistem feedback dan arahan yang cepat dalam komunikasi antara guru-murid.

Untuk itu diperlukan sebuah media pembelajaran interactive yang dapat memberikan siswa pengalaman belajar yang lebih menarik. Penelitian ini bertujuan untuk membangun aplikasi Multimedia interaktif Didukung metode adaptive learning. Adanya aplikasi multimedia ini juga bertujuan agar kualitas belajar siswa dapat lebih selalu ditingkatkan lagi.

\section{METODE/PERANCANGAN PENELITIAN}

Terdapat 3 tahap utama dalam penelitian ini, yaitu analisis kebutuhan, perancangan, pembuatan sistem. Tahapan penelitian ini secara keseluruhan dapat dilihat pada gambar 1 di bawah ini. 


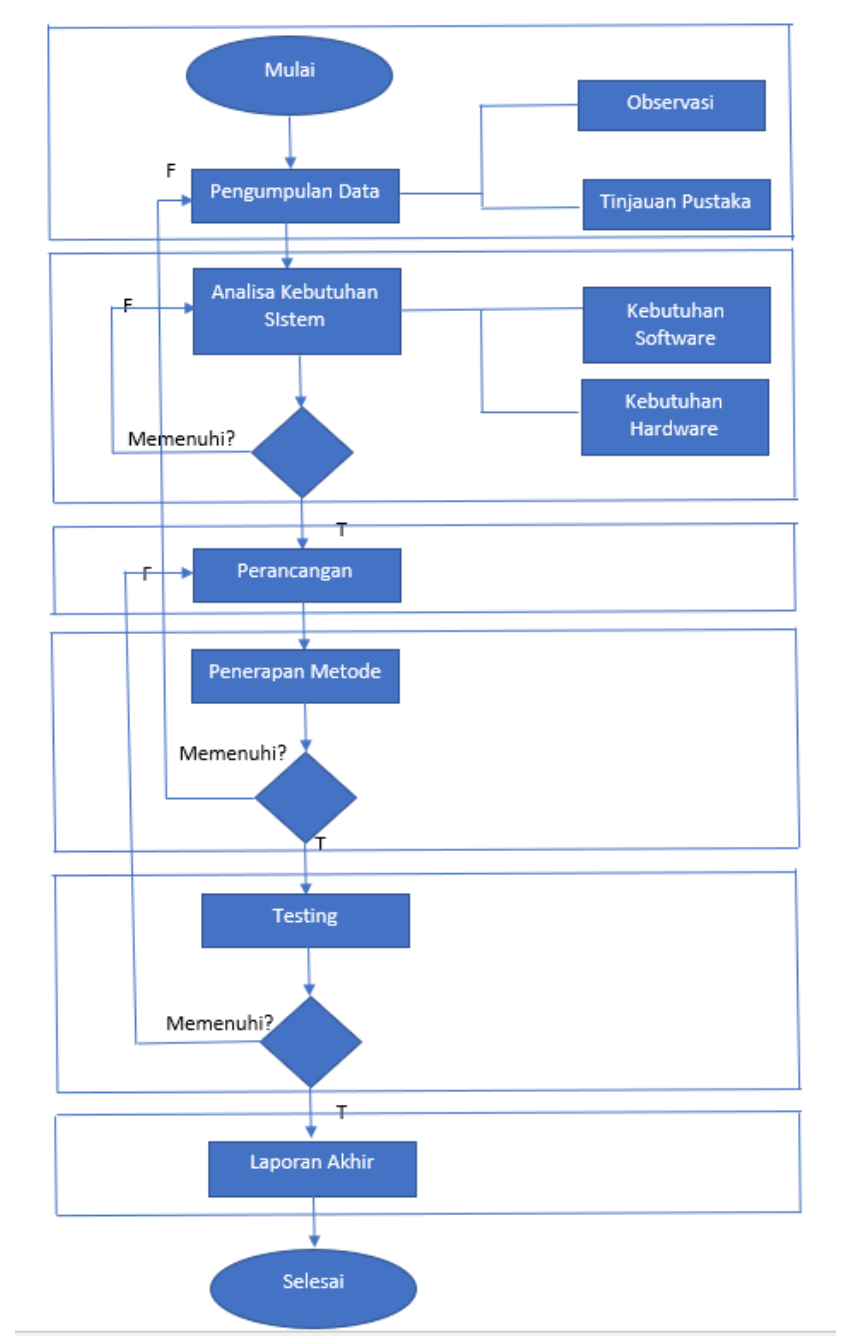

Gambar 1. Metode penelitian

1. Tahapan pengumpulan data ini dilakukan untuk mengumpulkan data terkait mata pelajaran sains, dan juga pengumpulan data gaya belajar siswa berdasarkan observasi lapangan yang akan dilakukan

2. Setelah itu penelitian melakukan analisis kebutuhan yang seperti apa yg dibutuhkan oleh masing-masing siswa berdasarkan gaya belajar setiap siswa.

3. Kemudian dilakukan perancangan aplikasi multimedia yang dirancang dalam bentuk games

4. Setelah rancangan sederhana aplikasi multimedia selesai kemudian diterapkanlah hasil dari metode adaptive learning kedalam aplikasi multimedia game tersebut.

5. Pada tahap testing dilakukan pengujian kepada siswa SD kelas 1.

6. Jika semua tahapan sudah selesai dan hasilnya sesuai dengan yang diharapkan maka, disusunlah laporan akhir.

Pada dasarnya penerapan dari metode adaptive learning ini sangat mudah, yaitu hanya mencari sample beberapa siswa untuk dilakukan testing aplikasi, kemudian diarahkan setiap siswa tersebut belajar atau bermain games sesuai dengan minatnya masing-masing. Hal tersebut terlihat bagaimana tingkat pembelajaran siswa dengan menggunakan atau menerapkan metode adaptive learning. 


\section{KILAT}

Vol. 10, No. 1, April 2021, P-ISSN 2089-1245, E-ISSN 2655-4925

DOI: https://doi.org/10.33322/kilat.v10i1.1156

Unung Verawardina (2017) Melalui aktivitas-aktivitas di dalam e-learningmahasiswa dapat belajar secara kolaboratif dengan mahasiswa lainnya. Mahasiswa dapat saling bekerja sama dalam timmelalui kelompok antarmahasiswa lainnya dan membangun komunikasi interaktif. Manfaatnya mengajarkan keterampilan untuk saling bekerja sama, belajar memecahkan masalah bersama, menumbuhkan rasa kebersamaan antaranggota kelompok, menambah pengetahuan,dan pengalaman anggota kelompok dalam belajar.

\section{HASIL DAN PEMBAHASAN}

Hasil dari penelitian yang diambil dari sample beberapa orang siswa SD kelas 1, maka dapat dilihat beberapa hasil seperti gambar yang dibawah ini yang menunjukkan aplikasi yang sama tapi penggunaan yang berbeda tergantu minat siswa tersebut kebagian mana

Media pembelajaran yang dibangun menggunakan aplikasi Unity. Dan dengan dilengkapi soal serta gambar yang menarik dari beberapa sumber yang di anggap berguna dan terpercaya

Adapun pelatihan yang dilakukan adalah terkait dengan fungsi aplikasi sebagai berikut, yaitu:

a. Halaman awal

b. Halaman soal bergambar dilengkapi skor

c. Halaman soal tidak bergambar dilengkapi skor

d. Halaman skor akhir

a. Halaman Awal

Halaman ini berisikan ucapan selamat datang untuk user yang akan melakukan tes atau ujian yang terdapat pada aplikasi. Halaman awal ini juga dilengkapi dengan tombol start yang jika user klik akan langsung masuk ke menu soal pertama seperta gambar 2 berikut.

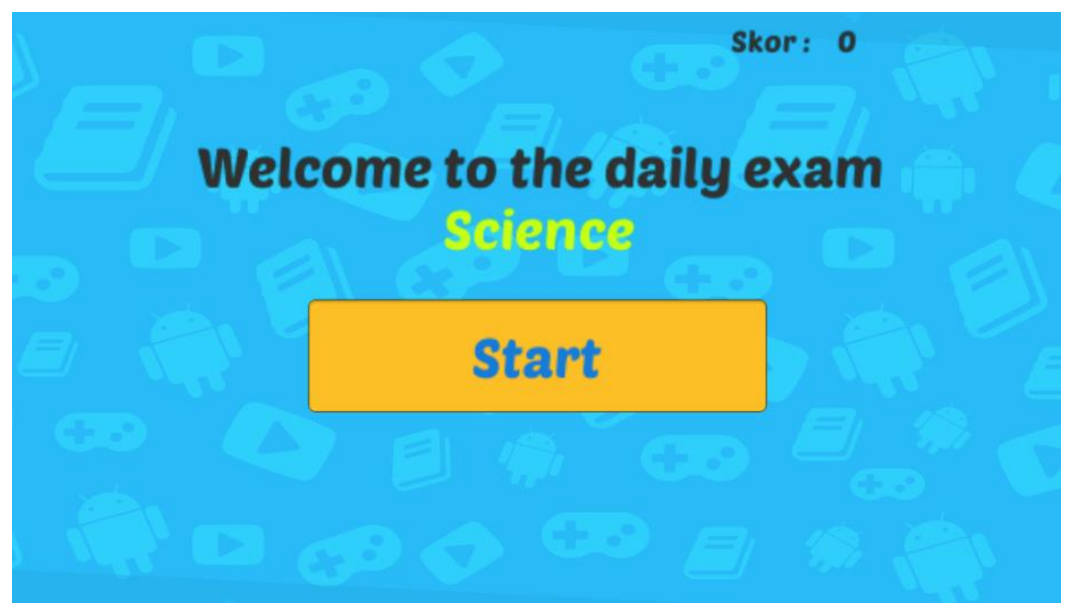

Gambar 2. Halaman awal

\section{b. Halaman Soal Bergambar Dilengkapi Skor}

Halaman ini berisikan soal yang telah diinputkan oleh perancang system berdasarkan data yang telah sesuai di dapatkan dari sumber yang jelas. Disini terlihat soal yang dilengkapi dengan gambar-gambar yang berguna untuk dapat menarik minat belajar siswa juga langsung berisikan suara yang memperdengarkan apa isi dari halaman soal tersebut. Pada halaman soal pertama ini juga dapat terlihat skor 0 yang menandakan bahwa game untuk belajar ini baru saja akan dimulai seperti gambar 3 berikut. 


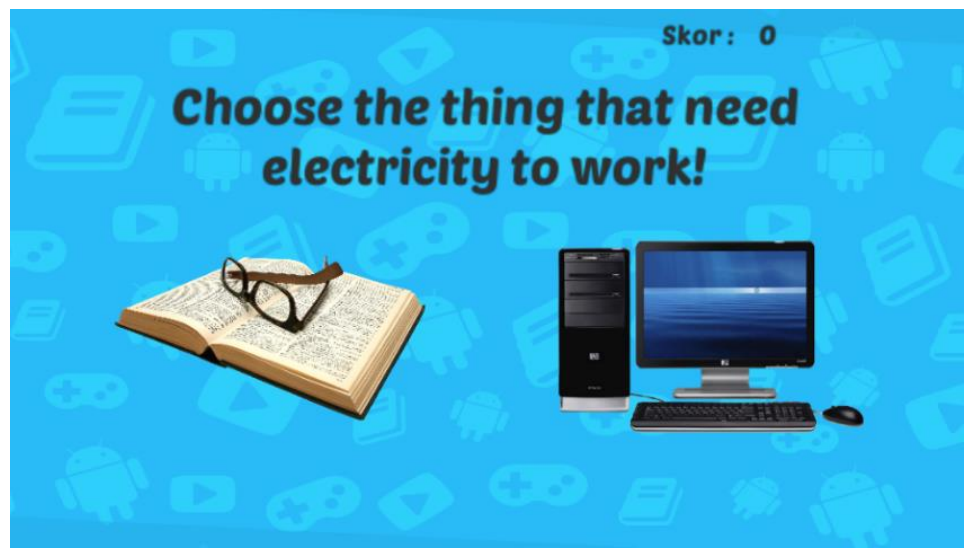

Gambar 3. Halaman soal bergambar dilengkapi skor

c. Halaman Soal Tidak Bergambar Dilengkapi Skor Visual

Selain dilengkapi dengan soal bergambar dan bersuara, game untuk ujian ini juga dilengkapi dengan soal tidak bergambar tapi tetap dilengkapi dengan suara untuk yang memiliki minat jenis audiovisual, hal ini berguna untuk membuat sebuah ujian dapat seperti beragam dan tidak membosankan (monoton) seperti gambar 4 seperti berikut ini :

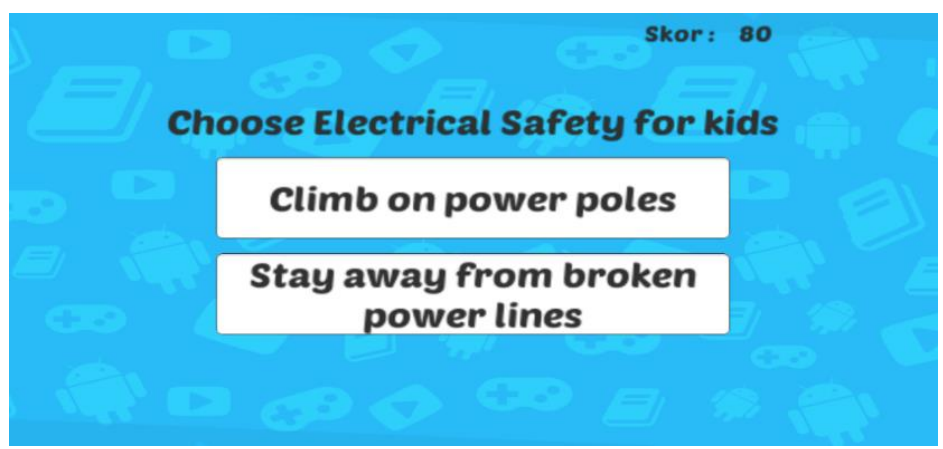

Gambar 4. Hasil Cetak Halaman Daftar Pengunjung

d. Halaman Skor Akhir Visual

Media pembelajaran berupa game ini pun juga di lengkapi fitur skor atau nilai akhir, skor atau nilai akhir ini didapatkan dari hasil penyelesaian soal yang telah mereka selesaikan seperti gambar 5 seperti berikut ini :

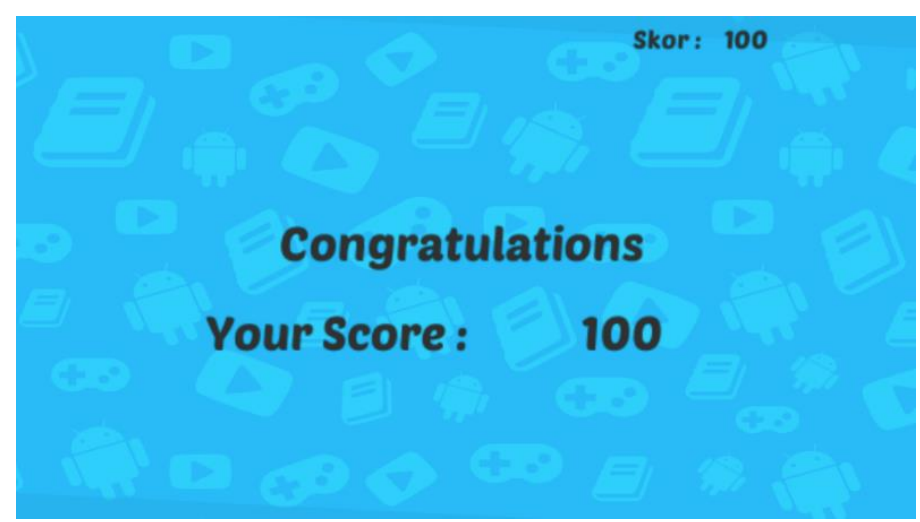

Gambar 5. Halaman Skor Akhir 


\section{KILAT}

Vol. 10, No. 1, April 2021, P-ISSN 2089-1245, E-ISSN 2655-4925

DOI: https://doi.org/10.33322/kilat.v10i1.1156

\section{KESIMPULAN DAN SARAN}

\subsection{Kesimpulan}

Setelah dilakukan penelitian dengan cara pengambilan data sample dari beberapa siswa, maka dapat terlihat bahwa tingkat prestasi ataupun minat siswa dalam belajar khususnya mata pelajaran Sains untuk kelas 1 SD meningkat. Dari penelitian yang telah dilakukan terdapat beberapa cara dalam menarik minat siswa SD dalam belajar yaitu dengan menerapkan metode Adaptive Learning, yang mana dengan menerapkan metode ini siswa dapat belajar sesuai dengan cara mereka sendiri dan juga menjadi semakin menarik.

\subsection{Saran}

Diharapkan Penelitian ini memiliki waktu yang lebih lagi sehingga dapat melakukan percobaan pada sample yang lebih banyak lagi. Tenaga professional juga dibutuhkan untuk selalu melakukan Update aplikasi ataupun sistem agar menjadikan sistem multimedia ini selalu up to date.

\section{UCAPAN TERIMAKASIH}

Penulis mengucapkan terima kasih kepada Institut Teknologi PLN yang telah memberi dukungan yang membantu pelaksanaan penelitian dan atau penulisan artikel.

\section{DAFTAR PUSTAKA}

[1] Abdulmajid, Nuur Wachid., et.al (2017). Penerapan E-Learning Sebagai Pendukung Adaptive Learning Dan Peningkatan Kompetensi Siswa Smk Di Kabupaten Bantul. Jurnal Taman Vokasi Volume 5, No 2, Desember 2017

[2] Balqis Fallahnda (2020). Mengenal Teknologi Pembelajaran Adaptive Learning dan Manfaatnya.Tirto.id

[3] Hernawati, kuswari (2011). E-Learning Adaptif Berbasis Karakteristik Peserta Didik. Prosiding Seminar Nasional Penelitian, Pendidikan dan Penerapan MIPA, Fakultas MIPA, Universitas Negeri Yogyakarta

[4] I Gede Jana Adi Putra, Dkk (2019). Adaptive Learning: Mengidentifikasi Gaya Belajar Peserta Didik Dalam Rangka Optimalisasi Sistem E-Learning Dengan Menggunakan Bayesian Network. Jurnal Ilmu Komputer Indonesia, (JIKI) Vol : 4, No. 2

[5] Kurniawati, inung diah., Nita, sekreningsih (2018). Media Pembelajaran Berbasis Multimedia Interaktif Untuk Meningkatkan Pemahaman Konsep Mahasiswa. Journal of Computer and Information Technology. Vol.1, No. 2, Febuary 2018. E-ISSN: 2579-5317

[6] Mustika., et.al (2017). Pengembangan Media Pembelajaran Interaktif dengan Menggunakan Metode Multimedia Development Life Cycle. JOIN (Jurnal Online Informatika) Volume 2 No. 2 | Desember 2017 : 121-126 DOI: 10.15575/join.v2i2.139.

[7] Rasyid, maghfirah., et.al (2016). Pengembangan Media Pembelajaran Berbasis Multimedia Dalam Konsep Sistem Indera Pada Siswa Kelas Xi Sma. Jurnal Pendidikan Biologi Volume 7, Nomor 2, Februari 2016 . Universitas Negeri Makassar

[8] Sirilius Seran (2016). Pengaruh Status Sosial Orang Tua Terhadap Motivasi Anak Untuk Sekolah Pada Perguruan Tinggi. Jurnal Pendidikan Ekonomi, Vol.09, No.2, 2016 DOI:https://dx.doi.org/10.17977/UM014v09i22016p149

[9] Surahman, ence., Surjono Herman Dwi (2017). Pengembangan Adaptive Mobile Learning Pada Mata Pelajaran Biologi Sma Sebagai Upaya Mendukung Proses Blended Learning. Jurnal Inovasi Teknologi Pendidikan Volume 4, No 1, April 2017. 
[10] Unung Verawardina (2017). Penggunaan Media Adaptive Andengaginge-Learningterhadap Keterampilanmahasiswa Dalam Membuatmedia E-Learning. Prodi Pendidikan Teknologi Informasi dan Komputer, IKIP PGRI Pontianak. Jurnal Pendidikan Informatika dan Sains, Vol.6, No. 1, Juni 2017. 